\title{
ЗАПАД И ВОСТОК: ГЕНЕТИКА ДУХОВНОГО ПУТИ
}

\author{
Махаматов T. T.
}

В статье речь идет об имманентных противоречиях, заложенных в самой природе, генетике Запада и Востока как неких макрополюсов мировой циивилизации, с одной стороны, и о сильнейшем влиянии глобализации на диалектику межиивилизационных отношений - с другой. Глобализационные проиессы, достигшие своего апогея в современном мире, отчетливо выявляют противоречия, определяют различные варианты их разрешения и особенности, действующие на всех уровнях человеческого бытия и сознания - от особенностей мировоззрения и мировосприятия в целом до прикладной хозяйственно-экономической деятельности в частности. Осмысление данного фактора объективной реальности, поиск форм и способов разречения противоречий межцивилизационных отношений может явиться важным элементом для наиболее адекватного и продуктивного жизненного пути человечества в современном мире.

Ключевые слова: ичивилизация, западный менталитет, восточная мудрость, макроциивилизации, глобализация, межцивилизацчионные отношения, противоречия, диалектика, демографическая лавина, многополярный мир, техногенность.

In this article, we speak about the immanent contradictions inherent in the very nature, the genetics of West and East as some macro-poles of world civilization, on the one hand, and about the strong influence of globalization on the dialectics of inter-civilizational relations, on the other. Globalization, which has reached its apogee in the modern world, clearly reveals the contradictions that define various options for their resolution and features operating at all levels of human existence and consciousness - the nature of the worldview and attitude, in general, and as applied to economic activities, in particular. Understanding this factor of objective reality, the search of forms and methods for the resolution of contradictions of inter-civilizational relations can be an important element for the most adequate and productive life path of humanity in the modern world.

Keywords: Civilization, Western mentality, the wisdom of the East, macrocivilizations, globalization, relations between civilizations, contradictions, dialectics, demographic avalanche, multipolar world, technology-relatedness.

Усиливающийся и устойчивый научный интерес к цивилизационной проблематике в рамках социально-философского дискурса побуждает к размышлениям о противоречиях современного этапа глобализации [Бахтуридзе 2017; Гранин 2017; Гринин 2013; Кочетов 2017; Чумаков 2017; Махаматов 2017], о порождаемой ею в западном мире массовой культуре, «новом классе»- прекариате [Стэндинг

\footnotetext{
* Махаматов Тимур Таирович - к. филос. н., Финансовый университет при Правительстве РФ. Е-mail: Timour.makhamatov@gmail.com.
}

Век глобализации 1/2018 60-67 
2014], с одной стороны, и о мире так называемых традиционных обществ, с их многовековыми ценностными системами и канонами - с другой [Махаматов 2007; Мигунов, Мигунова 2017].

Процесс глобализации с самого своего начала раскрывал, обострял актуальные имманентные противоречия человеческого мира и определял основные линии его дальнейшей эволюции. Нынешний этап глобализации на передний план выдвигает диалектику противоречий межцивилизационных отношений, актуализирует проблему нахождения адекватных форм, способов их разрешения и формирование такого глобального жизненного пространства, «где человек и мир составляют одно целое и являются “продлением” друг друга» [Мигунов, Мигунова 2017: 31].

Для современной цивилизации в целом характерна парадигма сосуществования, выживания и диалектического единения в условиях глобальных проблем. В настоящее время, как пишет Р. А. Нуруллин, «интеграция народов приобрела глобальный характер, что вновь на новом витке развития человечества актуализировало проблему необходимости синхронизации различных культур, но только на основе переосмысления не проблем начала бытия, а проблем, связанных с осознанием конечности существования человечества (эсхато)» [Нуруллин 2017: 84].

Что лежит в основе парадигмы диалектического единства макроцивилизаций? Для раскрытия основ противоречивости двух макроцивилизаций и их возможного позитивного взаимодействия следует рассмотреть то, что их различает. Современные процессы «постиндустриальной» технологизации, информатизации и в конечном счете - универсалистской глобализованности современной мировой циивилизации привели к сущностным противоречиям как между Западом и Востоком, так и на уровне конкретных локальных цивилизаций - по принципу «универсализм - партикуляризм», с одной стороны, и также к глубокому противоречию между материальным аспектом существования человека и общества и его духовным аспектом - с другой.

До начала XXI в. в мире господствовала прозападная цивилизация [Гранин 2017], которая в отличие от классических цивилизаций Востока содержит в своей основе иной, не восточный, духовный Путь, опирающийся на рационализм, иной комплекс морально-этических и духовных ценностей, исходящих из разумного эгоизма. В итоге чем совершеннее становятся технологии, тем слабее и беззащитнее в их среде чувствует себя человек-эгоист.

В связи со сказанным вспоминаются слова Махатмы Ганди о том, что материальное производство и промышленность в сущности необходимы человеку постольку, поскольку у него имеются минимальные, естественно насущные потребности; разрушительное противоречие возникает лишь тогда, когда человек в своем существовании все более и более начинает зависеть от машин и материального производства (которые, в свою очередь, диктуют человеку расширение потребления), усугубляя тем самым собственное бессилие и приближая себя к гибели.

В этой связи примечательны слова И. А. Василенко, справедливо заключившей, что «сегодня предельно поляризованное человечество, наконец, пришло к выводу, что необходимы поиски новой политической этики, существенно отличающейся от прогрессистской модели эгоистической заинтересованности и конкурентности», антропоцентризм которой «низводит духовность до неадекватно- 
го ей уровня и низводит природу до статуса объекта потребления» [Василенко 1999: 4].

Предмет, мотивация и методы философско-религиозного поиска в макроцивилизациях Востока и Запада различаются существенно. Путь развития макроцивилизации Запада экстравертен. В его основе никогда не существовало предпосылки следовать внутреннему естеству, природным и космическим законам, Пути самосовершенствования. Как раз наоборот, имманентно преобладало стремление подчинять и использовать - природу, общество рациональному человекуэгоисту и потребителю. Исторически имела место предельная рационализация духовной и общественно-политической жизни.

В итоге эпоха модерна, сменившись эпохой постмодерна, завершилась неким разочарованием Запада в осуществлении трех главных целей, поставленных в свое время эпохой Просвещения: подчинить человеческому ratio природу, общество, человека. Как пишет известный польский ученый Гж. В. Колодко, «усилия по вестернизации мира и особенно по его американизации потерпели неудачу... Политический неолиберализм из подлинной демократии делает посмешище, а экономический неолиберализм превращает экономику в свою частную ферму...» [Колодко 2017: 146].

В цивилизации Востока издревле преобладало стремление познать изначальные, непреходящие законы Естества, согласно которым, как считалось и считается, все исконно управляется и совершается (иначе говоря, высшее, универсальное начало, например, Дао, Дхарма, Святое Откровение, Атман, Воля Всевышнего), ибо лишь следуя этим законам, можно достичь истинного мира и гармонии, что и является, собственно, подлинным развитием, как полагали на Востоке. А. Фурсов, например, в данной связи справедливо отмечает: «В отличие от Запада, где изменение приравнивается к прогрессу, а прогресс является ценностью, в Бирме изменение не отождествляется с прогрессом. Буддизм учит: изменение неизбежно, но оно вовсе не значит ни линейность, ни сдвиг к лучшему, а потому нововведения и новизна не могут быть целями...» [Афро-азиатский... 1999: 78-79].

В этом аспекте можно говорить о существовании неких системообразующих элементов макроцивилизационного дискурса, таких как образ жизни, мировосприятие, миропонимание, ментальность, духовно-культурные ценности. Можно заключить, что данные факторы обусловили различие самих целей цивилизационного развития на Западе и Востоке, а также логики эволюции восточного и западного типов макроцивилизаций. Данная логика представляется противоречивыми тенденциями этого развития, такими как рационализм, техногенность, антропоцентричность, «условная дифференцированная реальность» - в западной макроцивилизации, и иррационализм, экофильность, теоцентричность, «безусловная целостная реальность», которая, согласно концепции геоцивилизации, выдвигаемой современными китайскими обществоведами во главе с Жуань Вэем, «является фактом “живой жизни”, а потому и воспринимается по-китайски “сердцем”, то есть сквозь призму наполненного теплом человеческого соприсутствия и вовлеченности» [Мигунов, Мигунова 2017: 31], - в восточной.

Возвращаясь к межцивилизационному аспекту современных глобальных проблем, отметим актуальнейшую, на наш взгляд, проблему: существует ли какаялибо позитивная перспектива дальнейшего развития межцивилизационных отношений в современном мире? Актуальность проблемы еще ярче выступает на фоне 
того, что, согласно рассуждениям Гж. В. Колодко, «во времена глобализации и присущей ей борьбы за влияние и положение честной политики не существует. Китай широко использует промышленный шпионаж... Американцы, русские, англичане, немцы, французы и японцы, а также другие нации тоже это делают» [Колодко 2017: 141].

Рассматривая в данной связи известный тезис американского ученого С. Хантингтона о неизбежном столкновении цивилизаций в XXI в., мы можем сказать, что, конечно, потенциально возможности столкновения макроцивилизаций существуют, но постольку, поскольку параллельно с ними существуют также и возможности позитивного диалога и сотрудничества, опирающиеся на потенциал, имманентно заложенный в самой сущностной основе каждой из макроцивилизаций. Однако как бы ни были объективны эти возможности и потенциалы, без субъективных факторов, без решения проблем глобального управления и регулирования [Урсул 2014; Чумаков 2010] они не могут быть реализованы.

На наш взгляд, возможность столкновения цивилизаций во многом определяется наличием или отсутствием и уровнем рационального мышления, принципами гуманизма, толерантности руководителей ведущих держав мира. Действительно, наглядный пример развития, который демонстрируют в наше время Япония и Китай, показывает, что возможно, скажем, совершать модернизацию восточного государства и общества, не просто заимствуя западные ценности, но сочетая, синтезируя технократическую культуру Запада с духовными традициями Востока, сохраняя при этом национальную культурную идентичность и самобытность цивилизации.

Хотя Восток всегда был самодостаточен в своем пути развития, притом что само понятие «развитие» всегда обладало иной семантикой, чем на Западе, объективный процесс глобализации вынуждает его заимствовать и адаптировать на своей почве западные ценности и элементы западной культуры и менталите$m a$. Участвуя в развитии межцивилизационных отношений в условиях углубляющейся и расширяющейся глобализации (что является закономерным следствием развития так называемой «западной половины человечества», о чем говорилось выше), Восток должен, так сказать, изучить этот «язык» современного глобализма и говорить на нем, для того чтобы выявить и некий собственный потенциал развития - рационального, техногенного, технократического. В то же время Запад лишь начинает осознавать необходимость культурных заимствований у Востока, продолжая считать самодостаточной ту систему ценностей, которую создала западная цивилизация в ходе своего исторического развития [Проблемы... 2016]. Осознание такой необходимости обусловлено как спецификой и логикой развития самой западной макроцивилизации, так и недавними последствиями глобализации. Как справедливо пишет Л. Е. Гринин, «развитие глобализации с некоторого момента оказалось несовместимым с устоявшейся моделью американской и западной гегемонии» [Гринин 2013: 66].

В этом же русле находится вышеупомянутая и анализируемая Н. И. и О. В. Мигуновыми концепция «геоцивилизационного континуума», разрабатываемая китайскими философами. «В этом отношении разработка китайскими обществоведами концепта "геоцивилизации" - очевидное свидетельство признания плюрализма цивилизаций и отказа от идеи цивилизационной исключительности Китая, - отмечают авторы. - Но по существу обращение к концепту “геоцивилизация” есть признание 
и чего-то большего, а именно - того обстоятельства, что мир все же сложнее, чем его представляет теория локальных цивилизаций; что мир как единое общечеловеческое цивилизационное целое состоит не из одних лишь цивилизационных образований как своих “слагаемых”...» [Мигунов, Мигунова 2017: 23].

Обусловленно наблюдается стремление западного человека сбалансировать перениманием духовных традиций, морально-этических канонов, культурных достижений Востока ту рационализированность, спланированность и техногенность окружающей его жизни, которая зачастую делает формальной даже систему ценностей, в которой он живет.

В настоящее время мы можем говорить о заимствованиях западным обществом культурных традиций Востока на уровне отдельных индивидов и мелких социальных групп (общин), хотя и в широких масштабах. Это выражается во все возрастающем личностном и групповом интересе западного человека к традиционным и нетрадиционным религиозно-философским системам Востока (буддизм, ислам, индуизм и др.), к национальным восточным культурно-философским традициям (таким, например, как японская икебана и чайная церемония, китайское искусство цүигун и тайщззц̧юань и т. п.), в создании соответствующих общин и обществ на Западе.

Обратимся, на наш взгляд, к достаточно глубокой и существенной для настоящего исследования парадигме - возможности достижения качественно иного уровня межцивилизационных отношений в современном мире.

Для развития искусства межцивилизационного «гуманистического» политического диалога необходимо в корне пересмотреть саму общую парадигму конфликта цивилизаций. Содержательную концепцию такой парадигмы развила И. А. Василенко. Так, анализируя два типа взаимодействия - взаимодействие интересов и взаимодействие ценностей, она отмечает, что модель «столкновения интересов» работает только в рамках одной цивилизации (одной картины «мира»). Здесь действительно интересы сопоставимы и соизмеримы в рамках одной системы ценностей. Их можно объективизировать, схематизировать, представить в виде причинно-следственной связи и, наконец, согласовать.

При столкновении цивилизаций (и индивидуальных «миров»), подчеркивает И. А. Василенко, «необходима другая парадигма конфликта - модель “столкновения ценностей”, при том, что ценности разных культур несопоставимы и несоизмеримы, среди них не может быть никаких универсальных “эталонов”, заданных одной из сторон. Иначе цивилизации (“миры”) будут неравноправны в своем взаимодействии» [Василенко 1999: 246].

Образно говоря, ведя разговор об одном предмете и употребляя одни и те же понятия, представители разных цивилизаций будут иметь в виду на самом деле вещи различные, понимая их согласно ценностным традициям своей цивилизации. К примеру, когда западные люди говорят с людьми Востока о мире, то первые имеют в виду некий консенсус в обоюдных интересах, сдерживающий на какое-то время взаимную агрессию заинтересованных сторон (либо агрессию и адекватный ответ на нее) либо удовлетворяющий интересы этих сторон, а вторые - по сути преобразованное состояние души и сознания враждовавших сторон, интересы же при этом решаются вторичным порядком.

Обобщая смысл вышеизложенного, можно сделать вывод о том, что межцивилизационные отношения, являясь по сути процессом взаимодействия различ- 
ных, порою даже сущностно противоположных, систем ценностей, практически выражаются на современном этапе их развития во взаимодействии систем интересов этих цивилизаций (макроцивилизаций). Это, в свою очередь, обусловливает предпосылки к межцивилизационному столкновению, о котором ведут речь некоторые западные ученые, в частности С. Хантингтон.

Однако следующим, качественно новым и весьма необходимым для дальнейшего позитивного развития современного мирового сообщества этапом в формировании межцивилизационных отношений должен явиться осознанный качественный переход этих цивилизаций (макроцивилизаций) в их взаимодействии друг с другом от приоритета парадигмы интересов к приоритету парадигмы ценностей.

В обсуждении данной проблемы представляется более правильным анализировать дилемму возможности взаимодействия макроцивилизаций не с позиции парадигмы конфликта - интересов или ценностей, а с позиции парадигмы взаимодействия цивилизаций (макроцивилизаций). Такой «гуманистический диалог» может стать возможным при условии преодоления некоего социокультурного эгоцентризма как Запада, так и Востока, то есть более позитивного и открытого подхода друг к другу.

Так, И. А. Василенко отмечает: «Каждая из цивилизаций должна реабилитировать опыт других культур не только как равноправный, но и как расширяющий горизонт собственного бытия. Через гуманистический диалогизм осуществляется понимание культурой себя самой в прогрессе понимания других. Диалог актуализирует потребность культуры выйти за границь своей “самости”, включить в свое самосознание человека другой культуры, совершенно иного, с другой картиной мира и другими смыслами бытия (курсив мой. - T. М.). Этот взгляд “из-за зеркалья" на свое собственное бытие и сознание становится подчас решающим для активизации творческих возможностей культуры, а иногда и для коренного изменения процесса ее развития» [Василенко 1999: 248].

Закономерным результатом такого качественного перехода на более совершенную ступень в межцивилизационных отношениях неизбежно станет проявление взаимного уважения во взаимоотношениях цивилизаций и преодоление, по словам Жака Ле Гоффа, «псевдодиалога между Востоком и Западом, Севером и Югом» [Ле Гофф 2001: 18], что, в свою очередь, позволит цивилизациям (макроцивилизациям) осуществлять взаимное культурное обогащение и более эффективно сотрудничать в решении глобальных проблем современного мира.

А. С. Панарин отмечает: «Гуманизировать историю - значит реабилитировать принцип множественности субъектов истории в противовес монологу авангарда (гегемона), воплощающего своей волей единственно верный вариант ее развития». Это, на наш взгляд, и должно стать смыслом своего рода «гуманизации истории», «мучительного рождения нового этапа человеческой истории» [Панарин 1994: 41]. Данная задача сегодня является основной для всей мировой цивилизации.

Говоря о смене парадигмы взаимоотношений (поскольку совершенно естественно, что парадигма интересов во взаимоотношениях Запада и Востока как существовала прежде, так и будет существовать всегда) Запада и Востока в современном мире - с парадигмы интересов на парадигму иенностей, вернее, о необходимости приоритета последней над первой, следует иметь в виду, что для 
реализации подобного рода качественного совершенствования межцивилизационных отношений необходимы некие значительные мотивационные предпосылки.

Одной из значимых причин возникновения таких предпосылок, на наш взгляд, является реальность современных глобальных проблем, встающих все острее и актуальнее перед всем мировым сообществом, независимо от цивилизации. «Если нам удастся должным образом направить и контролировать постоянный диалог цивилизаций, - пишет Гж. В. Колодко, - то не будет их разрушительных столкновений, а возникнет творческая гармония» [Колодко 2017: 146]. Только всеобщее осознание необходимости совместного решения этих проблем поистине общепланетарного масштаба (как по своим причинам, так и по реальным и возможным последствиям) в условиях интегрированности и целостности современного мира, от разумного и позитивного разрешения которых зависит будущее человечества, может привести к подлинному диалогу ценностей между Востоком и Западом, к развитию межцивилизационных отношений качественно иного порядка. Здесь следует иметь в виду особенности культурно-цивилизационных систем Европы, США, Востока, в частности Китая и Ирана, и господствующие в них менталитеты, о тонкостях которых метко пишет А. Н. Чумаков, что оправдывает величину цитаты из его недавно опубликованной работы: «...в то время как Европа проявляет определенную осторожность и осмотрительность в международных делах, Соединенные Штаты Америки как относительно молодая культурно-цивилизационная система ведут себя несколько иначе. Американцы - прагматики и потому мыслят по большей части тактически, на короткие дистанции. Они не любят и не хотят ждать...

Иначе обстоит дело с культурно-историческими системами, история которых насчитывает многие столетия и тысячелетия. Там мыслят стратегическими категориями на длинные дистанции и умеют ждать: не спешат ни в словах, ни в делах, добиваясь поставленных целей» [Чумаков 2017: 16-17].

Диалектика межцивилизационных отношений Востока и Запада - этих двух великих феноменов, которые представила перед глазами цивилизованного человека история всей человеческой цивилизации и мысли, - заложена в глубинах самой сущности обеих макроцивилизаций, и достичь этих глубин в познании, надеемся, еще предстоит человеческой мысли и гуманизму. Здесь не должно быть места категоричности вроде той, что региональным или мировым лидером должна стать какая-либо страна [см.: Ковалев 2017: 14]. Конкретное государство становится лидером на основе устойчивого развития своей реальной экономики и тонкой международной политики. А это, в свою очередь, означает для цивилизации необходимость суметь подняться на качественно иную ступень духовного совершенства, что особенно важно для обеспечения ее дальнейшего сосуществования и выживания в новом, еще одном тысячелетии в развитии мировой цивилизации.

\section{Литература}

Афро-азиатский мир: региональные исторические системы и капитализм: проблемно-тематический сборник / сост. А. И. Фурсов. М. : ИНИОН РАН, 1999.

Бахтуридзе 3. 3. Международные отношения в эпоху «пост»: возможность эволюции // Век глобализации. 2017. № 3. С. 113-120. 
Василенко И. А. Диалог цивилизаций: социокультурные проблемы политического партнерства. М. : Эдиториал УРСС, 1999.

Гранин Ю. Д. Запад и альтернативные стратегии модернизации // Век глобализации. 2017. № 3. С. 17-30.

Гринин Л. Е. Глобализация тасует мировую колоду (Куда сдвигается глобальный экономико-политический баланс) // Век глобализации. 2013. № 2. С. 63-78.

Ковалев Ю. А. Новая геополитическая реальность и вопросы идеологии // Век глобализации. 2017. № 4. С. 14-22.

Колодко Гж. В. Эра Азии на фоне евро-атлантической цивилизации? // Вопросы экономики. 2017. № 10. С. 140-147.

Кочетов Э. Г. Парадигма Мирового Преображения как модель будущего (ее суть в максимально сжатом виде) // Век глобализации. 2017. № 3. С. 51-60.

Ле Гофф Ж. Средневековый мир воображаемого. М. : Прогресс, 2001.

Локальные цивилизации в XXI веке: столкновение или партнерство? Материалы к X Междисциплинарной дискуссии, Кострома, 21 мая 1998 года / под ред. проф. Ю. В. Яковца. М., 1998.

Махаматов Т. Т. О диалоге цивилизаций // Вестник Финансового университета. 2007. № 1. C. 109-115.

Махаматов Т. М. От эпохи глобализации к неоглобализации: культурноцивилизационный аспект // Век глобализации. 2017. № 4. С. 55-61.

Мигунов Н. И., Мигунова О. В. О теоретических основаниях китайской концепции «геоцивилизационного континуума» // Век глобализации. 2017. № 2. С. 20-36.

Нуруллин Р. А. Идеология в условиях становления глобальной цивилизации // Век глобализации. 2017. № 2. С. 83-92.

Панарин А. С. Введение в политологию. М. : Новая школа, 1994.

Проблемы языка в глобальном мире: монография / под ред. Е. В. Ганиной, А. Н. Чумакова. М. : Проспект, 2016.

Стэндинг Г. Прекариат: новый опасный класс. М. : АЙРИС, 2014.

Урсул А. Д. Глобальное управление: эволюционные перспективы // Век глобализации. 2014. № 1(13). С. 16-27.

Чумаков А. Н. Глобальный мир: проблема управления // Век глобализации. 2010. № 2(6). С. 3-15.

Чумаков А. Н. Грядущая демографическая лавина: на пороге Великого переселения народов // Век глобализации. 2017. № 2. С. 3-19. 